\title{
Editorial: Innovations in teaching and course delivery
}

\author{
Alicja Syska \\ University of Plymouth
}

How do you deliver a lecture when you can't see your audience? How do you create enjoyable learning communities, connect with your students, and capture their imagination? How do you help your learners overcome the confined spaces of their rooms and the sense of containment and isolation felt when separated from others? How do you make literature matter when people around you are dying and news flashes about the pandemic induce desperation and panic? How do you motivate students, monitor their engagement, help them work in groups? How do you adapt to unprecedented increases in participants' numbers on a course? How do you adjust your resources and cope with change? These are the questions our authors had to answer and innovate around to ensure not only smooth and effective but also compelling and inspiring delivery of their specialist courses in the face of the forced move to remote learning.

This section brings together the reflections of academic tutors and lecturers who strove to identify and implement the most effective ways of delivering teaching in their disciplines. The range of specialisms among the authors is remarkable: here we have representatives of Arts and Humanities, English Literature and Psychology, Bioscience and Biology, Teacher Training and Marketing. Regardless of the discipline, they all display the same commitment, ingenuity and resilience in responding to the unwelcome disruption. A Fine Art lecturer decides to teach with short stories while an English Literature professor turns to the theme of the sixteenth century plague for its transformative possibilities and reassurance in a time of crisis. Reading together with students, seeking engagement through regular feedback, and watching lectures 'live' as a unified cohort prove to be as effective as carefully designing group work or motivating students to engage with course material by challenging them to 'escape' topical rooms by demonstrating and testing their knowledge. When participants' number double due to the pivot to online delivery, teaching student centred learning can still be achieved by diversifying assignments, restructuring 
cohorts to prevent depersonalised learning experience, and encouraging reflection to promote wellbeing and resilience.

All the authors make insightful observations about the learning activities they tested and the experiences they gained by responding to their particular teaching challenges. Some reflected on their long held assumptions about what works well in education while others recognised the transformative potential of seemingly undesirable modifications and interventions. The recommendations they make for other practitioners will be invaluable in rethinking, redesigning, and changing the direction of future university practice. 